\title{
Fabrication of PDMS/GA Composite Materials by Pickering Emulsion Method and Its Application for Oil-Water Separation
}

\author{
Biao Wang ${ }^{1}$, Qingwang Liu ${ }^{1, *}$, Zhenzhong Fan ${ }^{1, *}$, Ting Liang ${ }^{2, *}$, Qilei Tong ${ }^{1}$ and Yuanfeng Fu ${ }^{1}$ \\ 1 Petroleum Engineering College, Northeast Petroleum University, Daqing 163318, China; \\ lovepeacht@163.com (B.W.); neputongqilei@163.com (Q.T.); fufpetroleum@126.com (Y.F.) \\ 2 South China Advanced Institute for Soft Matter Science and Technology, \\ South China University of Technology, Guangzhou 510006, China \\ * Correspondence: liuqingwang@163.com (Q.L.); fanzhenzhong@163.com (Z.F.); 1t900201@scut.edu.cn (T.L.)
}

Citation: Wang, B.; Liu, Q.; Fan, Z.; Liang, T.; Tong, Q.; Fu, Y. Fabrication of PDMS/GA Composite Materials by Pickering Emulsion Method and Its Application for Oil-Water Separation. Energies 2021, 14, 5283. https://doi.org/10.3390/en14175283

Academic Editor: Tanvir Qureshi

Received: 25 July 2021

Accepted: 23 August 2021

Published: 26 August 2021

Publisher's Note: MDPI stays neutral with regard to jurisdictional claims in published maps and institutional affiliations.

Copyright: (c) 2021 by the authors. Licensee MDPI, Basel, Switzerland. This article is an open access article distributed under the terms and conditions of the Creative Commons Attribution (CC BY) license (https:// creativecommons.org/licenses/by/ $4.0 /)$.

\begin{abstract}
With the intensification of human activities, a large amount of oil and organic solvent waste has been created, resulting in serious ecological and environmental pollution. Therefore, how to balance environmental benefits and economic benefits control a large number of organic solvent and oil pollution is an urgent problem. To solve this problem, a highly efficient oil-water separation material was designed and prepared in this paper. Graphene oxide aerogels were synthesized by the Pickering emulsion and hydrothermal method, and then hydrophobically lipophilic polydimethylsiloxane (PDMS) reduced graphene oxide aerogel composites (PDMS/GA) were obtained by modification of PDMS. The surface functional groups, hydrophobicity, thermal stability, and micromorphology of the materials were tested by various characterization methods. Their properties were tested by an oil absorption test and repeated experiments. The oil absorption performance experiments and repeated performance experiments of PDMS/GA are reported. The number of oxy-gen-containing functional groups of the modified graphene oxide (GO) decreased, and the contact angle of water was $134.4^{\circ}$. The adsorption capacity of $n$-hexane was up to 18.5 times its own weight. The material has the advantages of being lightweight, easy to recover, good hydrophobicity and lipophilicity, and has the potential for large-scale applications in the field of oil-water separation.
\end{abstract}

Keywords: PDMS; graphene oxide; aerogel; nanomaterials; oil-water separation

\section{Introduction}

In the 21st century, there are a many problems in the scientific field that need to be studied in depth, such as the energy crisis [1,2] and environmental pollution issues $[3,4]$. There is an urgent need for lightweight, high porosity, environmentally friendly, and sustainable materials with high mechanical properties in many emerging research fields such as energy storage [5,6], sensors [7,8], thermal insulation materials [9,10], adsorption [11,12], and so on. If any material can be called the king of lightweight, graphene oxide (GO) with the largest specific surface area must be the first choice $[13,14]$. GO has abundant oxygen-containing functional groups $[15,16]$, which allows it to be active in many reactions. The material synthesized as a raw material has high porosity [17,18], low density [19,20], and low thermal conductivity [21,22], which has attracted widespread attention.

Hydrophobic graphene aerogel (GA) synthesized by the hydrothermal method, due to its high oil absorption performance, no pollution to the environment, and good selective oil absorption performance in water, makes it a relatively good choice in the treatment of marine oil spill accidents [23,24]. However, in terms of practical application, due to the easy coalescence of GO during the initial reaction, its products often have problems such as high brittleness, fragility, hygroscopicity, and non-renewability, which limit its commercial use [25-27]. In order to obtain higher porosity and lower density of graphenebased nanocomposites, better mechanical strength, and an increase in the dispersion of 
GO in the initial reaction, the preparation of Pickering emulsion before the hydrothermal reaction is a solution to the dispersion of GO.

In 2010, Kim et al. [28] first proposed and verified that GO can form a very stable Pickering emulsion due to its parental characteristics. Li et al. [29] verified through experiments that GO's Pickering emulsion is an oil-in-water emulsion. Song et al. [30] reported that GO stabilized styrene/water Pickering emulsion can produce polystyrene coated with graphene oxide. Kulkarni et al. used the Pickering emulsion method to synthesize hydrophobic GA through freeze-drying and high-temperature annealing, but there is no doubt that the raw materials and experimental conditions used in this synthesis are far from being applicable to industrial mass production [31].

In this study, we used a simple mechanical stirring method to mix GO, ethylenediamine, n-hexane, and deionized water to form a Pickering emulsion to increase the dispersion of GO. Next, through a hydrothermal reaction, GO was combined through the $\pi-\pi$ bond forces to obtain graphene oxide hydrogel. The hydrogel was dialyzed with a hydroalcoholic solution to remove n-hexane, and then lyophilized to obtain GA, modified by Polydimethylsiloxane (PDMS) to obtain PDMS/GA. The microscopic morphology and structure of the composite aerogel were characterized, and the adsorption capacity of the composite aerogel for n-hexane was studied.

\section{Materials and Methods}

\subsection{Materials}

Flake graphite (325 mesh 99.6 wt\%; Nanjing Xianfeng Nanomaterials Technology Co., Ltd., Nanjing, China), concentrated sulfuric acid $\left(\mathrm{H}_{2} \mathrm{SO}_{4} 98 \%\right.$; Beijing Chemical Reagent Factory, Beijing, China), potassium permanganate $\left(\mathrm{KMnO}_{4} 99.5 \%\right.$; Beijing Chemical Reagent Factory, Beijing, China), sodium nitrate (AR Tianjin Chemical Reagent Factory, Tianjin, China), hydrogen peroxide $\left(\mathrm{H}_{2} \mathrm{O}_{2} 30 \%\right.$; Shanghai Civic Chemical Technology Co., Ltd., Shanghai, China), ethylenediamine (Shanghai Civic Chemical Technology Co., Ltd., Shanghai, China), PDMS (Dow Corning Corporation 184), and n-hexane (Shanghai Civic Chemical Technology Co., Ltd., Shanghai, China).

\subsection{Instruments and Characterization}

LEICA DM2500P microscope and supporting instruments (DM2500P polarizing microscope (Leica, Wetzlar, Germany); JY-PHB type contact angle measuring instrument (Chengde Jinhe Instrument Manufacturing Co., Ltd., Chengde, China); DHG-9030A type vacuum drying oven (Shanghai Yiheng Technology Co., Ltd., Shanghai, China); Panalytical model X-ray diffraction Instrument (Netherlands PANalytical, Almelo, Netherlands); Thermo Fisher Nicolet Is5 model FTIR (Thermo Fisher, Waltham, America); Thermo Scientific Apreo 2C model field emission scanning electron microscope (Beijing Obertong Optical Technology Co., Ltd., Beijing, China).

\subsection{Methods}

\subsubsection{Preparation of GO}

The preparation method of GO adopted the hummers' method, and the preparation method was improved. The main preparation method was: add $23 \mathrm{~mL}$ of concentrated sulfuric acid into a three-necked flask and placing the flask in an ice water bath, with the temperature less than $8{ }^{\circ} \mathrm{C}$. Add $1 \mathrm{~g}$ of natural flake graphite powder and $0.5 \mathrm{~g}$ of $\mathrm{NaNO}_{3}$ under the condition of constant stirring, add $3 \mathrm{~g}$ of $\mathrm{KMnO}_{4}$ to it after $3 \mathrm{~min}$, and continue to stir and react for $2 \mathrm{~h}$. Then, the temperature was raised to $35^{\circ} \mathrm{C}$ and reacted for $35 \mathrm{~min}$. After that, $46 \mathrm{~mL}$ of deionized water was added to the three-necked flask and the temperature was raised to $98^{\circ} \mathrm{C}$. After stirring the reaction for $20 \mathrm{~min}, 5 \mathrm{~mL}$ of $\mathrm{H}_{2} \mathrm{O}_{2}$ $(5 \%)$ was added to neutralize the excess $\mathrm{KMnO}_{4}$, and then transferred to the refrigerator. After cooling overnight, the obtained solution was washed repeatedly with $0.1 \mathrm{~mol} / \mathrm{L}$ dilute hydrochloric acid and deionized water and transferred to a drying box for drying to obtain GO. 


\subsubsection{Preparation of GA by the Pickering Emulsion Method}

Disperse $20 \mathrm{mg}$ of graphene oxide into $5 \mathrm{~mL}$ of deionized water, add $20 \mu \mathrm{L}$ of ethylenediamine, $2 \mathrm{~mL}$ of $\mathrm{n}$-hexane, and stir at high shear for $20 \mathrm{~min}$ to obtain a Pickering emulsion. The formed Pickering emulsion is shown in Figure 1. Put the solution into a high temperature and high pressure reactor with a polytetrafluoroethylene lining, heat it at $180^{\circ} \mathrm{C}$ for $10 \mathrm{~h}$, cool it naturally to room temperature, take out the graphene oxide hydrogel, and dialyze it several times with a hydroalcoholic solution at $-30^{\circ} \mathrm{C}$. After freezing for $12 \mathrm{~h}$ and freeze-drying for $48 \mathrm{~h}$, graphene oxide aerogel was obtained.

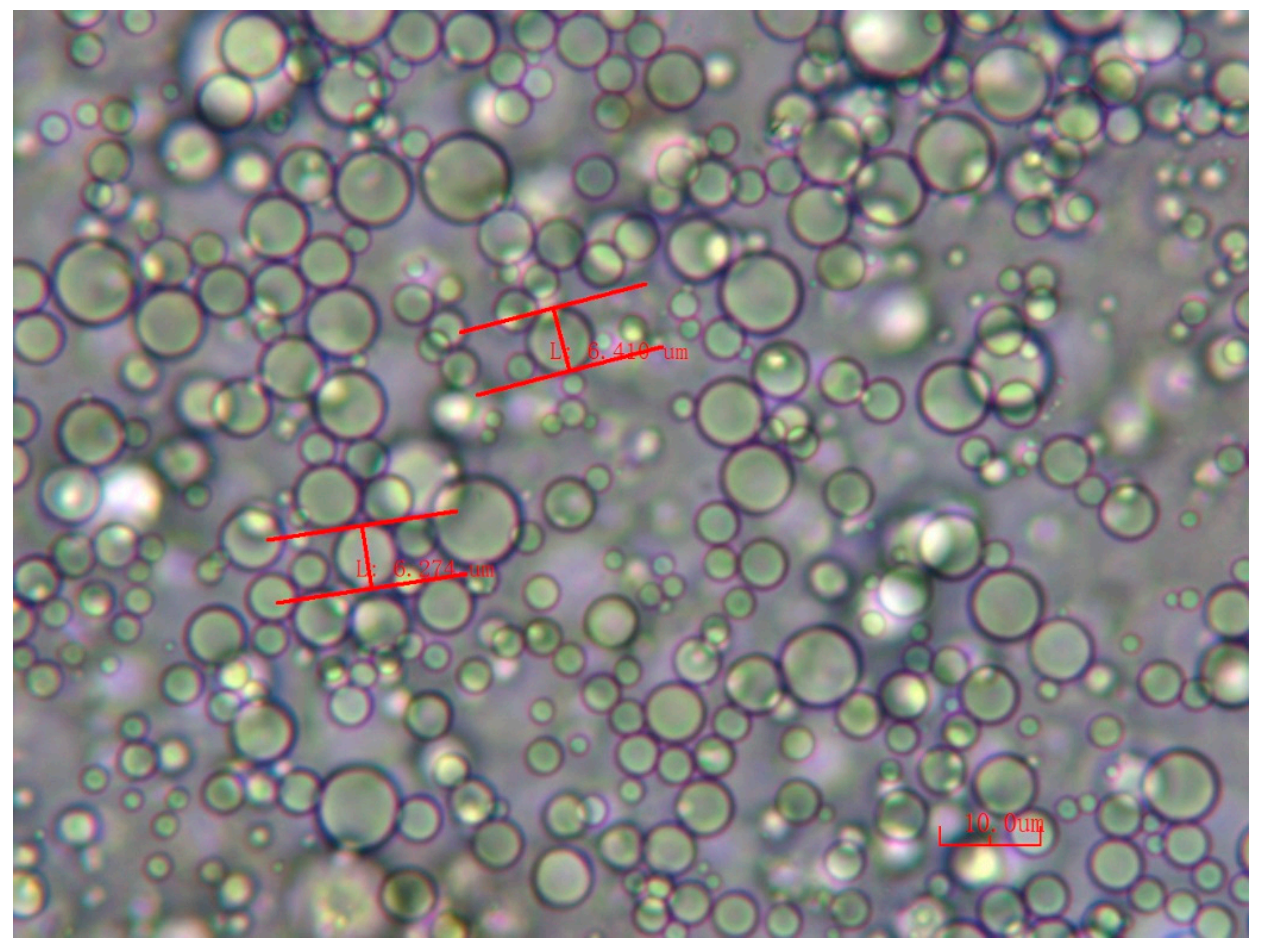

Figure 1. Micrograph of graphene oxide Pickering emulsion.

\subsubsection{PDMS Modified Graphene Oxide Aerogel}

Dissolve $1.1 \mathrm{~g}$ PDMS in $50 \mathrm{~mL}$-hexane solution (PDMS purchased from Dow Corning 184, $1 \mathrm{~g}$ A glue and $0.1 \mathrm{~g}$ B glue were mixed for use), immerse the graphene oxide aerogel in an appropriate amount of PDMS. The solution was heated in a vacuum drying oven at $60^{\circ} \mathrm{C}$ for $2 \mathrm{~h}$ to pre-cure the PDMS, then the cured aerogel was further processed at $120^{\circ} \mathrm{C}$ for $6 \mathrm{~h}$ to obtain an aerogel sample. As shown in Figure 2, a final graphene oxide aerogel that can be supported on flowers is obtained. 


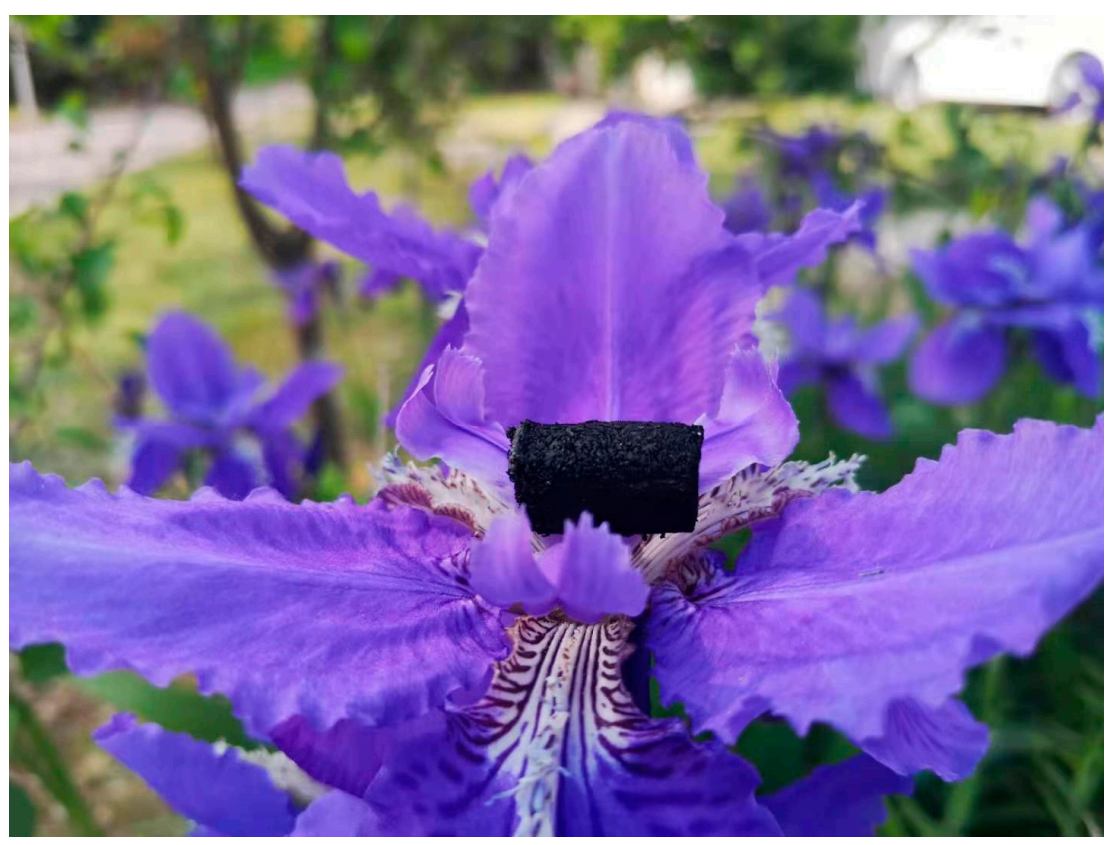

Figure 2. Graphene oxide aerogel easily supported by flowers.

\section{Results}

\subsection{Chemical Composition Analysis of GO, GA, and PDMS/GA}

Figure 3 reports X-ray diffraction (XRD) patterns of GO, GA and PDMS/GA. There was a very sharp diffraction peak at $2 \theta=10.990^{\circ}$ and the interlayer spacing was 8.0441 . This is due to the presence of oxygen-containing functional groups such as hydroxyl carboxyl groups on the GO surface, which leads to the presence of intercalated water molecules. The improved interlayer spacing and the graphene oxide synthesized in other literature [32] was basically the same. From the XRD pattern of GA, it can be seen that a wider diffraction peak was observed at $2 \theta=24.014^{\circ}$, the corresponding interlayer spacing was $\mathrm{d}=0.37027 \mathrm{~nm}$. The intensity of the diffraction peak was reduced, the diffraction peak became wider and the sharp diffraction peak disappeared. These changes indicate that the oxygen-containing functional group indicated by GO was removed by the hydrothermal reduction reaction, which reduced the interlayer spacing of GA and improved the hydrophobicity to a certain extent. From the XRD pattern of PDMS/GA, it can be seen that the modified PDMS/GA was in an amorphous state.

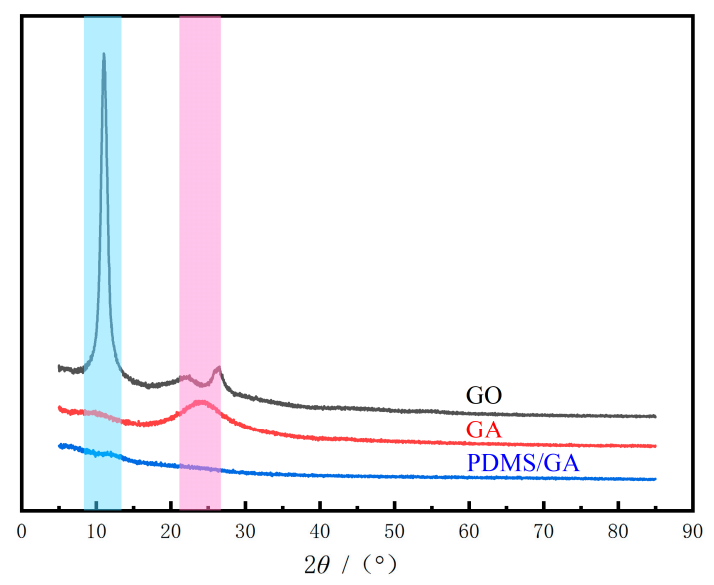

Figure 3. XRD of raw GO, GA and PDMS/GA (The blue shade indicates $2 \theta=10.990^{\circ}$; The purple shade indicates $2 \theta=24.014^{\circ}$ ). 
In Figure 4, since all samples were freeze-dried or vacuum-dried and then subjected to thermogravimetric treatment, there was no significant quality degradation at $25-120{ }^{\circ} \mathrm{C}$. The first significant thermal weight-loss stage of GO was $150-240{ }^{\circ} \mathrm{C}$. The weight loss in this stage was mainly caused by the decomposition of oxygen-containing functional groups in GO; after $240^{\circ} \mathrm{C}$, the slow decrease in the mass of GO was also caused by the decomposition of oxygen-containing functional groups; After $475{ }^{\circ} \mathrm{C}$, its mass continued to decrease, which was due to the change in mass caused by the burning of amorphous carbon in the graphite powder during the test. GA and PDMS/GA continued to decrease slowly from $150{ }^{\circ} \mathrm{C}$, which indicated that the unreduced oxygen-containing groups disappeared. At $475^{\circ} \mathrm{C}$, the amorphous carbon in the gel starts to burn, so there is a significant thermal weight loss stage. At $730^{\circ} \mathrm{C}$ due to PDMS, the combustion of the silicone rubber formed after curing leads to changes in the quality development and a significant thermal weight loss stage.

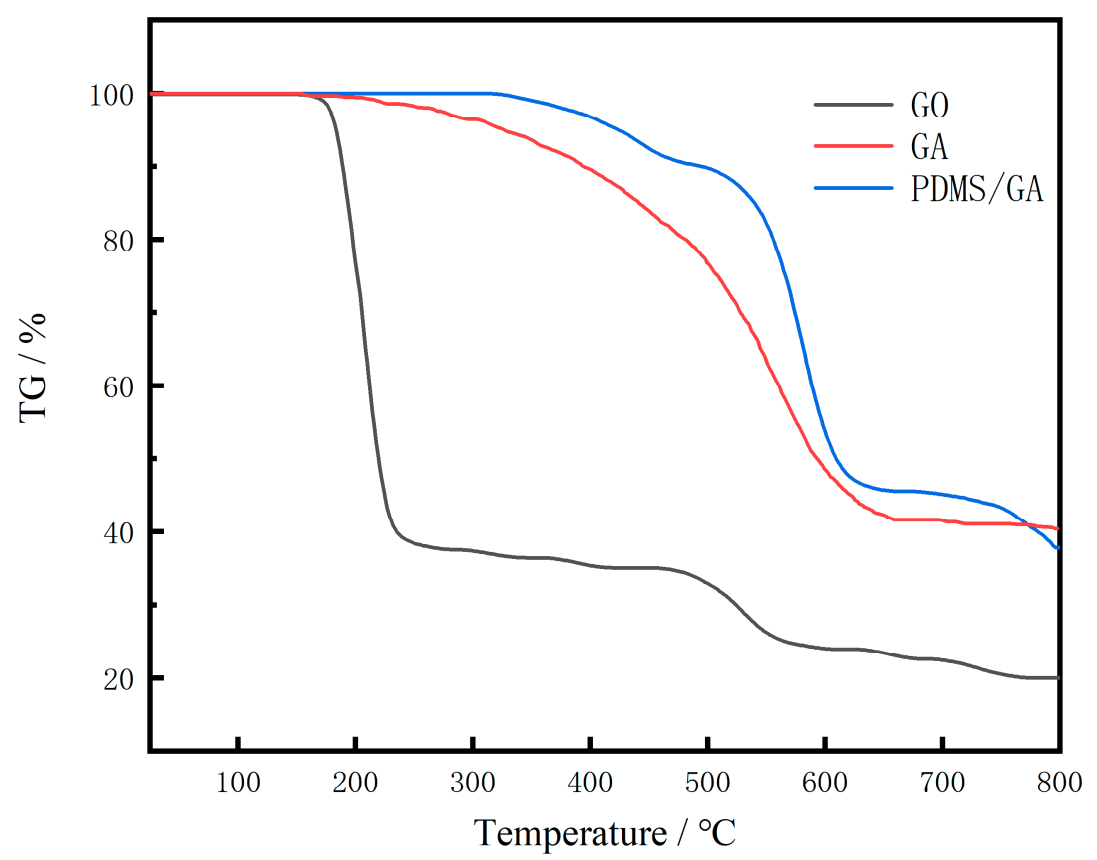

Figure 4. The GO of raw GO, GA, and PDMS/GA.

The infrared spectrum of GO is shown in Figure 5. There are strong characteristic peaks at $3446 \mathrm{~cm}^{-1}$ (stretching vibration of $-\mathrm{OH}$ ), absorption peaks at $1403 \mathrm{~cm}^{-1}$ (deformation vibration of $-\mathrm{OH}$ ), and $1110 \mathrm{~cm}^{-1}$ (stretching vibration of $\mathrm{C}-\mathrm{O}-\mathrm{C}$ ); all are caused by the oxygen-containing functional groups. It is worth noting that, compared with $\mathrm{GO}$, the $3446,1403,1110 \mathrm{~cm}^{-1}$ peaks in the infrared spectrum of GA almost disappeared, and the band of oxygen-containing functional groups decreased significantly, which proved that graphene oxide was effectively reduced and the material was hydrophobic and lipophilic. Performance has been improved to a certain extent.

In the infrared spectrum of PDMS-GA, there is the C-H strong symmetrical stretching vibration peak of $-\mathrm{CH}_{3}\left(2963 \mathrm{~cm}^{-1}\right)$, the in-plane bending vibration peak of $\mathrm{Si}-\mathrm{CH}_{3}$ $\left(1262 \mathrm{~cm}^{-1}\right)$, the stretching vibration peak of Si-O-Si $\left(1092 \mathrm{~cm}^{-1}\right)$, and the symmetric stretching vibration peak of Si-O-Si bond $\left(801 \mathrm{~cm}^{-1}\right)$. The appearance of these new characteristic peaks indicates that PDMS was successfully grafted onto GA. Since the oxygen-containing groups on the PDMS/GA surface are greatly reduced at this time, the hydrophobic and lipophilic properties of the material are improved.

In Figure 6, GO has many oxygen-containing groups, exhibits hydrophilic characteristics, and has a contact angle of $56.7^{\circ}$ to water. Ethylenediamine is used as a cross-linking agent and reducing agent to obtain graphene oxide aerogels with a contact angle of $81.3^{\circ}$ 
by the Pickering emulsion method. This is because the surface contains too many oxygen groups and cannot achieve super-hydrophobicity. When further modified, the gel prepared by the Pickering emulsion method has better elasticity and tighter structure.

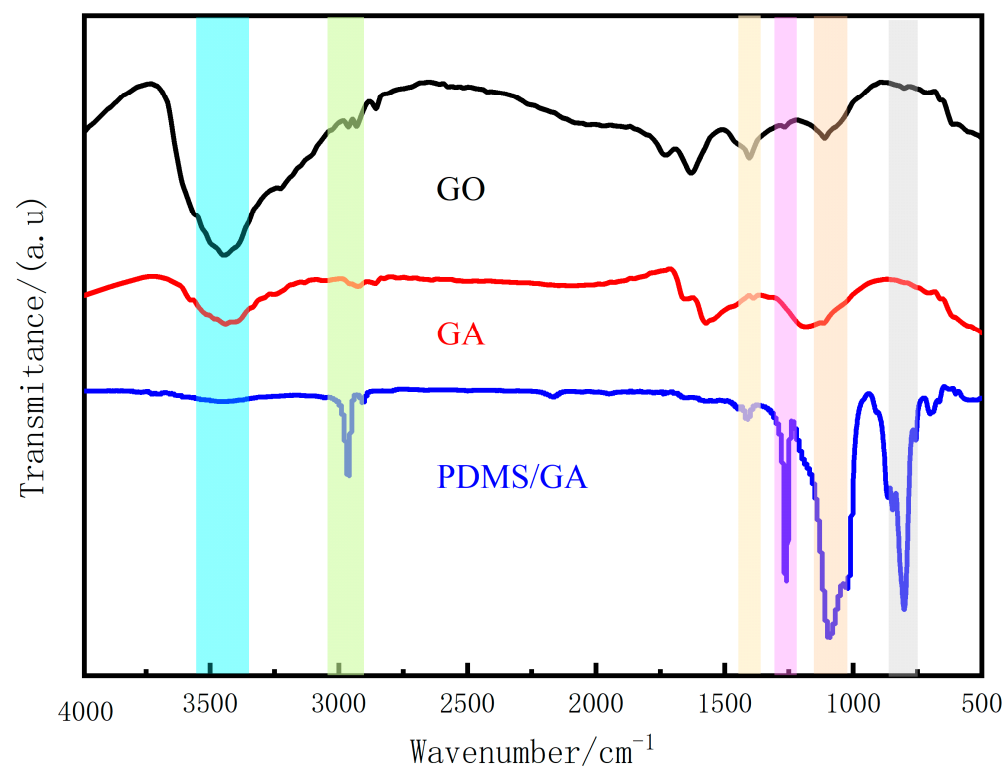

Figure 5. FTIR spectra of raw GO, GA, and PDMS/GA (the shadows from left to right are $3446 \mathrm{~cm}^{-1}$, $2963 \mathrm{~cm}^{-1}, 1403 \mathrm{~cm}^{-1}, 1262 \mathrm{~cm}^{-1}, 1092 \mathrm{~cm}^{-1}$, and $\left.801 \mathrm{~cm}^{-1}\right)$.

(a)

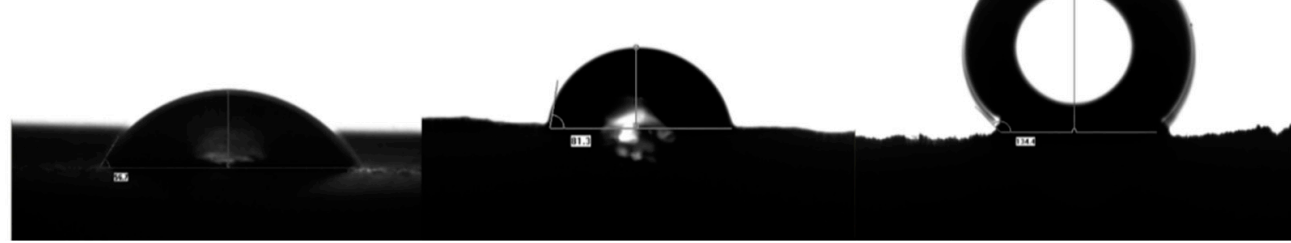

Figure 6. (a) Contact angle of GO; (b) Contact angle of GA; (c) Contact angle of PDMS/GA.

As an excellent hydrophobic modification substance, PDMS can not only hydrophobically modify graphene oxide, but also solidify the overall shape of aerogel so that the aerogel will not deform in the next high-temperature reduction. After the PDMS is cured at $60{ }^{\circ} \mathrm{C}$, the graphene oxide aerogel is further reduced at a high temperature. Under vacuum and $120^{\circ} \mathrm{C}$, the oxygen-containing group chemical bonds of graphene oxide are broken at high temperature, forming small molecules of water and carbon dioxide. Due to the solidification of PDMS, the interlayer spacing between graphene oxide sheets remains unchanged, and the graphene oxide aerogel with a hydrophobic angle of $134.4^{\circ}$ is finally obtained.

Figure $7 \mathrm{a}, \mathrm{b}$ shows GA prepared by the Pickering emulsion method at $95^{\circ} \mathrm{C}$ under high pressure. It can be found that the pores of graphene oxide folds are uniform and small owing to the use of n-hexane oil droplets as a template for the fold pores. Figure $7 \mathrm{c}, \mathrm{d}$ shows the PDMS/GA. It is found that the outer layer of the modified aerogel is evenly covered with a layer of silicone rubber. Compared with the first two synthetic products, PDMS/GA composite materials by the Pickering emulsion method can still maintain the pore morphology. This means it can be used as a good oil-absorbing material. 


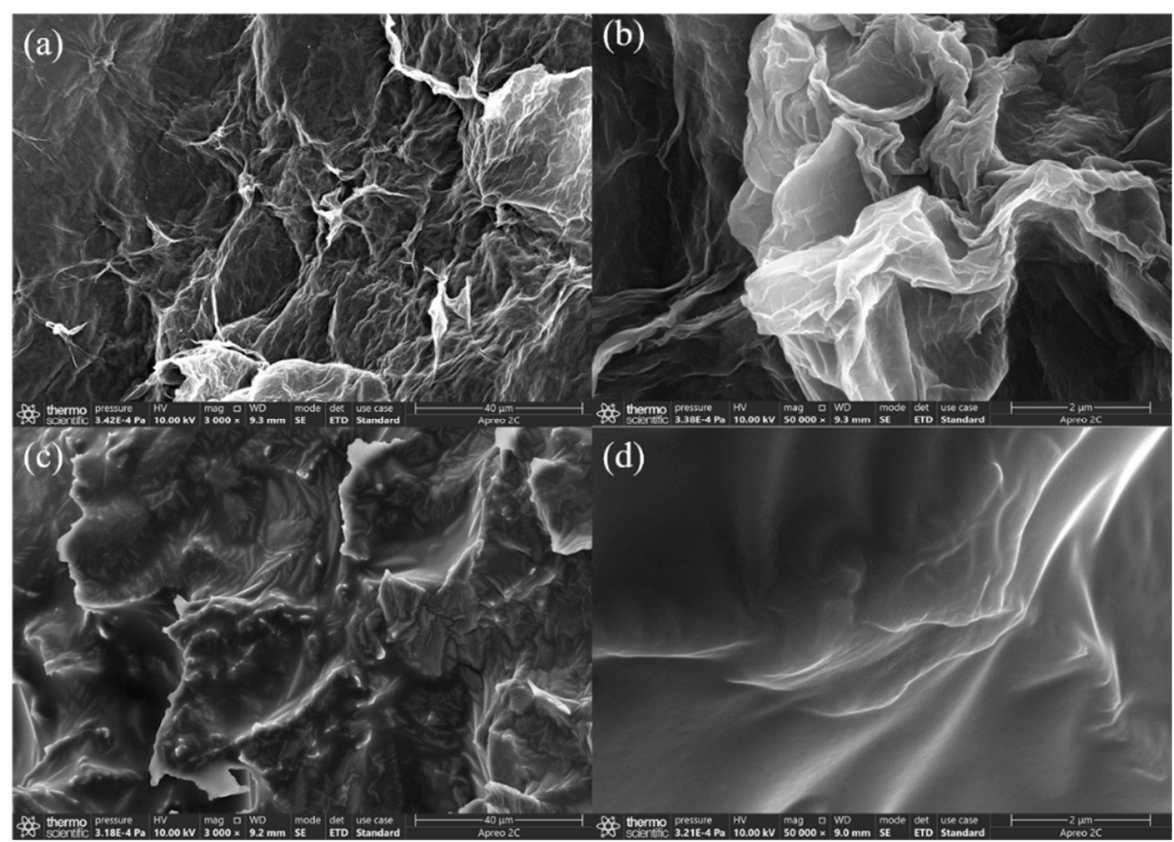

Figure 7. Scanning electron microscope (SEM) of raw GA and PDMS/GA. $(\mathbf{a}, \mathbf{b})$ is SEM of GA; $(\mathbf{c}, \mathbf{d})$ is SEM of PDMS/GA.

\subsection{Oil Absorption Test}

Figure 8 reported the test chart of the adsorption performance of PDMS/GA, all $\mathrm{n}$-hexane in the liquid surface could be adsorbed within $4 \mathrm{~s}$. The adsorption capacity can reach $18.5 \mathrm{~g} / \mathrm{g}$. After evaporating n-hexane at high temperature, repeated adsorption of n-hexane still shows excellent adsorption performance, it can still adsorb about 10 times of n-hexane after five cycles, which is shown in Figure 9.

Dai et al. [33] prepared a three-dimensional macroscopic superhydrophobic magnetic porous carbon aerogel with popcorn as raw material; its adsorption capacity for corn oil was $10.28 \mathrm{~g} / \mathrm{g}$. He et al. [34] reported a kind of Superhydrophobic bacterial cellulose $/ \mathrm{SiO}_{2}$ aerogels (BCAs/SAs); its adsorption capacity for corn oil was $8-14 \mathrm{~g} / \mathrm{g}$. The biodegradable cellulose aerogel prepared by Zhao et al. [35] could absorb 10 times its own weight.
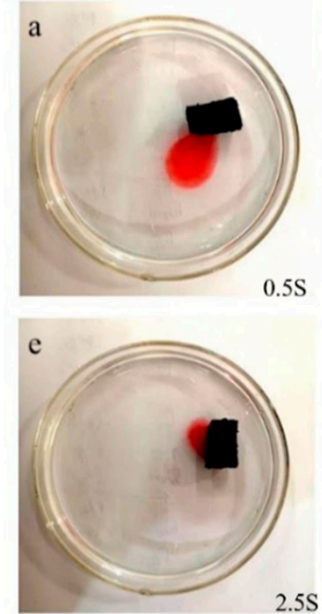
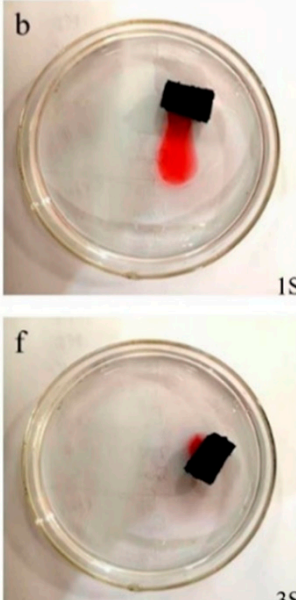
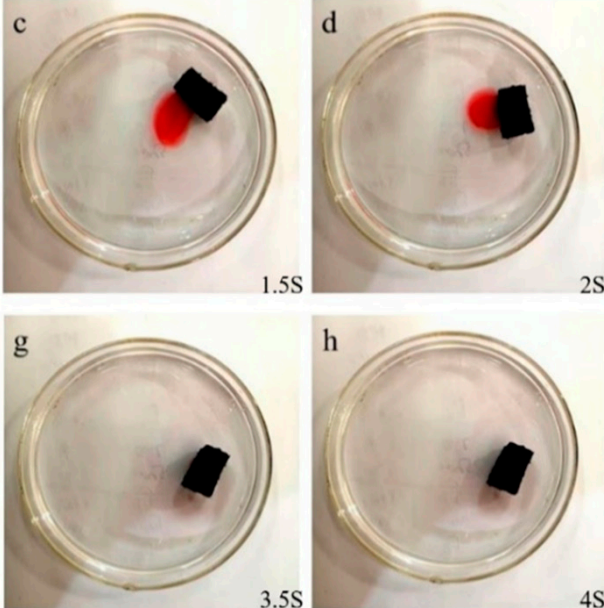

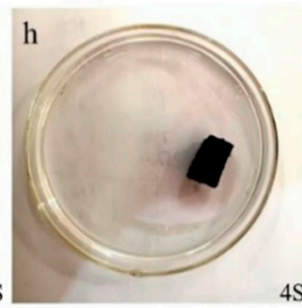

Figure 8. The test chart of the adsorption performance of PDMS modified graphene oxide aerogel on oil red-dyed $\mathrm{n}$-hexane. (a-h) is a photo taken every $0.5 \mathrm{~s}$ of adsorption. 


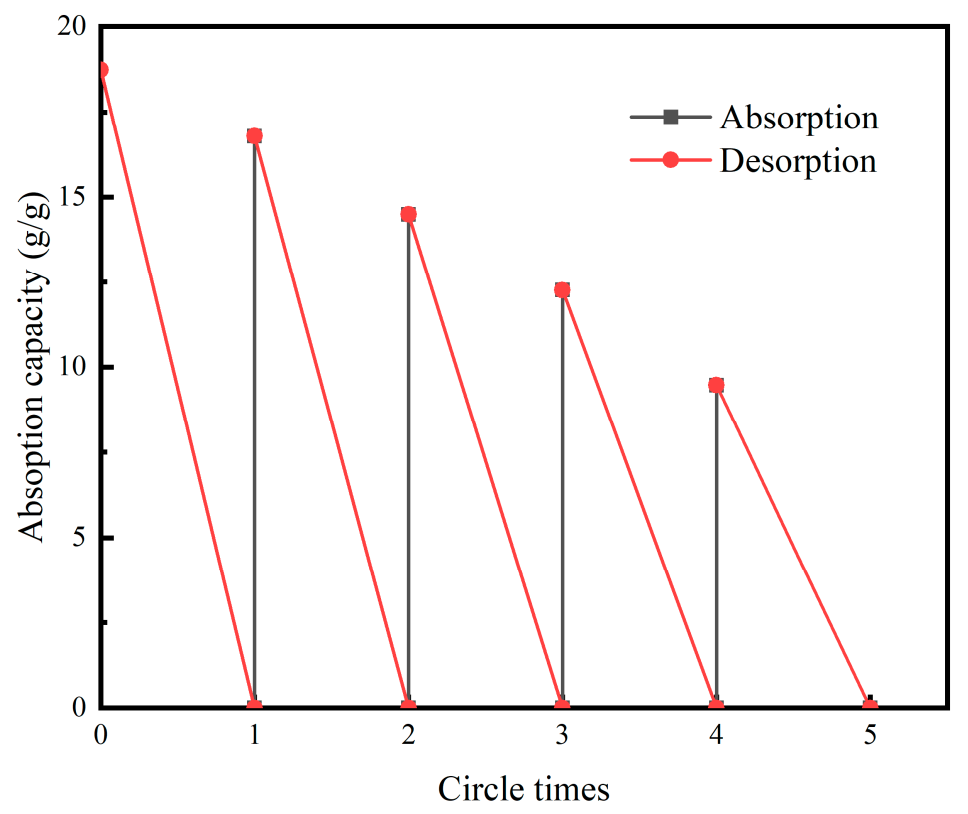

Figure 9. Absorption-desorption recyclability of PDMS/GA for n-hexane.

Compared with the above research, the adsorption capacity of PDMS/GA on oil-water mixture was improved.

\section{Discussion}

In summary, a graphene oxide aerogel was modified by PDMS by the Pickering emulsion method with a trace amount of ethylenediamine as a cross-linking agent and reducing agent. The advantages of PDMS/GA are that it has good elasticity, no pollution, strong adsorption capacity for pollutants, and easy recycling and regeneration. The prepared graphene oxide aerogels have a loose and porous structure, and pollutants can fill the pores so that the reduced graphene foam has certain adsorption characteristics for pollutants. Aerogels have good adsorption performance for organic solvents and oil pollutants, and their adsorption capacity of n-hexane can be up to 18.5 times. At the same time, the recyclability of the aerogel makes PDMS/GA widely used in practical applications.

Author Contributions: Writing —original draft preparation, formal analysis, investigation, B.W.; conceptualization, writing - review and editing, Q.L., Z.F. and T.L.; resources and visualization, T.L., Q.T. and Y.F. All authors have read and agreed to the published version of the manuscript.

Funding: The project is Supported by Heilongjiang Province Natural Science Foundation of "Study on flocculation of oilfield wastewater with magnetic nano-materials $\mathrm{Fe}_{3} \mathrm{O}_{4} @ \mathrm{SiO}_{2}-\mathrm{NH}_{2}$ ". Fund No.: LH2020E014.

Acknowledgments: I am very grateful to my friends, Leipeng Leng, Mingyang Zhang, and Chenyi You for their long-term care of me in life and experiments. Most of the scientific research starts from curiosity to solve a puzzle. It is meant to be fun and needs to be creative. Learning and experimenting are parts of life; learn to love yourself first and then love others. I love you so much. Thanks again.

Conflicts of Interest: The funders had no role in the design of the study; in the collection, analyses, or interpretation of data; in the writing of the manuscript, or in the decision to publish the results.

\section{References}

1. Melin, H. Towards a solution to the energy crisis. Nat. Astron. 2020, 4, 837-838. [CrossRef]

2. Ouyang, Y.; Shi, L.; Bai, X.; Li, Q.; Wang, J. Breaking scaling relations for efficient $\mathrm{CO}_{2}$ electrochemical reduction through dual-atom catalysts. Chem. Sci. 2020, 11, 1807-1813. [CrossRef]

3. Walker, T.R. Canada right to classify single-use plastics as toxic. Nature 2021, 594, 496. [CrossRef] [PubMed] 
4. Mai, L.; He, H.; Bao, L.J.; Liu, L.Y.; Zeng, E.Y. Plastics Are an Insignificant Carrier of Riverine Organic Pollutants to the Coastal Oceans. Environ. Sci. Technol. 2020, 54, 15852-15860. [CrossRef] [PubMed]

5. Sun, W.; Wang, F.; Zhang, B.; Zhang, M.; Winter, M. A rechargeable zinc-air battery based on zinc peroxide chemistry. Science 2021, 371, 46-51. [CrossRef]

6. Hafiz, H.; Suzuki, K.; Barbiellini, B.; Tsuji, N.; Viswanathan, V. Tomographic reconstruction of oxygen orbitals in lithium-rich battery materials. Nature 2021, 594, 213-216. [CrossRef]

7. Rogers, C.; Piggott, A.Y.; Thomson, D.J.; Wiser, R.F.; Nicolaescu, R. A universal 3D imaging sensor on a silicon photonics platform. Nature 2020, 590, 256-261. [CrossRef] [PubMed]

8. Purnell, B.A. Bioenergetic sensor for exercise. Science 2020, 370, 806-807.

9. Qian, X.; Zhou, J.; Chen, G. Phonon-engineered extreme thermal conductivity materials. Nat. Mater. 2021, 20, 1188-1202. [CrossRef]

10. Almeida, C.; Ghica, M.E.; Ramalho, A.L.; Dures, L. Silica-based aerogel composites reinforced with different aramid fibres for thermal insulation in Space environments. J. Mater. Sci. 2021, 56, 13604-13619. [CrossRef]

11. Lokamani, M.; Kelling, J.; Ohmann, R.; Meyer, J.; Kühne, T.; Cuniberti, G.; Wolf, J.; Huhn, T.; Zahn, P.; Moresco, F. A combined experimental and theoretical study of 1,4-bis(phenylethynyl)-2,5-bis(ethoxy)benzene adsorption on Au(111). Surf. Sci. 2021, $712,121877$.

12. Ye, R.; Zhao, M.; Mao, X.; Wang, Z.; Chen, P. Nanoscale cooperative adsorption for materials control. Nat. Commun. 2021, $12,4287$. [CrossRef]

13. Gao, J.; Yan, Q.; Lv, L.; Tan, X.; Dai, W. Lightweight thermal interface materials based on hierarchically structured graphene paper with superior through-plane thermal conductivity. Chem. Eng. J. 2021, 419, 129609. [CrossRef]

14. Di, S.; Feng, F.; Han, H.; Ma, Z. Prominent adsorption performance of amino-functionalized ultra-light graphene aerogel for methyl orange and amaranth. Chem. Eng. J. 2017, 324, 1-9.

15. Sun, J.; Hwang, J.Y.; Jankowski, P.; Xiao, L.; Jankowski, P. Critical Role of Functional Groups Containing N, S, and O on Graphene Surface for Stable and Fast Charging Li-S Batteries. Small 2021, 17, 2007242. [CrossRef]

16. Liu, Y.; Li, Y.; Yuan, X.; Ren, R.; Lv, Y. A self-prepared graphene oxide/sodium alginate aerogel as biological carrier to improve the performance of a heterotrophic nitrifier. Biochem. Eng. J. 2021, 171, 108027. [CrossRef]

17. Malik, S.; Gul, I.H.; Baig, M.M. Hierarchical MnNiCo ternary metal oxide/graphene nanoplatelets composites as high rated electrode material for Supercapacitors. Ceram. Int. 2021, 47, 17008-17014. [CrossRef]

18. Shaikh, J.S.; Shaikh, N.S.; Mishra, Y.K.; Pawar, S.S.; Parveen, N.; Shewale, P.M.; Sabale, S.; Kanjanaboos, P.; Praserthdam, S.; Lokhande, C.D. The implementation of graphene-based aerogel in the field of supercapacitor. Nanotechnology 2021, 32, 362001-362023. [CrossRef] [PubMed]

19. Kuila, T.; Bose, S.; Chang, E.H.; Uddin, M.E.; Khanra, P.; Kim, N.H.; Lee, J.H. Preparation of functionalized graphene/linear low density polyethylene composites by a solution mixing method. Carbon 2011, 49, 1033-1037. [CrossRef]

20. Kuila, T.; Bose, S.; Mishra, A.K.; Khanra, P.; Kim, N.H.; Lee, J.H. Effect of functionalized graphene on the physical properties of linear low density polyethylene nanocomposites. Polym. Test. 2012, 31, 31-38. [CrossRef]

21. Mortazavi, B.; Fan, Z.; Pereira, L.; Harju, A.; Rabczuk, T. Amorphized graphene: A stiff material with low thermal conductivity. Carbon 2016, 103, 318-326. [CrossRef]

22. Kim, J.C.; Wi, J.H.; Ri, N.C.; Ri, S.I. Thermal conductivity of graphene/graphane/graphene heterostructure nanoribbons: Non-equilibrium molecular dynamics simulations. Solid State Commun. 2021, 328, 114249. [CrossRef]

23. Lza, B.; Xin, X.C.; Cca, B.; Bca, B. Facile synthesis of porous $\mathrm{CoFe}_{2} \mathrm{O}_{4}$ /graphene aerogel for catalyzing efficient removal of organic pollutants. Sci. Total Environ. 2021, 775, 143398.

24. Liu, H.; Gao, B.; Yuan, W.; Li, H.; Chen, Z. Modification of graphene aerogel with titania nanotubes for efficient methylene blue adsorption kinetics. J. Sol-Gel Sci. Technol. 2021, 97, 271-280. [CrossRef]

25. Huang, J.; Huang, X.; He, M.; Zhang, B.; Feng, G.; Yin, G.; Cui, Y. Control of graphene aerogel self-assembly in strongly acidic solution via solution polarity tuning. RSC Adv. 2019, 9, 21155-21163. [CrossRef]

26. Zhao, Z.; Richardson, G.F.; Meng, Q.; Zhu, S.; Ma, J. PEDOT-based composites as electrode materials for supercapacitors. Nanotechnology 2015, 27, 042001. [CrossRef]

27. Wang, B.; Liu, Q.; Fan, Z. A Mini Review: Application Progress of Magnetic Graphene Three-Dimensional Materials for Water Purification. Front. Chem. 2020, 8, 595643. [CrossRef]

28. Kim, J.; Cote, L.J.; Kim, F.; Yuan, W.; Shull, K.R.; Huang, J. Graphene oxide sheets at interfaces. J. Am. Chem. Soc. 2010, 132, 8180. [CrossRef]

29. Li, Y.; Sun, Y.; Chen, J.; Zhu, X.; Li, H.; Huang, S.; Hu, Y.; Qi, C.; Zhong, S. Graphene oxide as a sacrificial material for fabricating molecularly imprinted polymer via Pickering emulsion polymerization. RSC Adv. 2016, 6, 74654-74661. [CrossRef]

30. Song, X.; Yang, Y.; Liu, J.; Zhao, H. PS colloidal particles stabilized by graphene oxide. Langmuir 2011, 27, 1186-1191. [CrossRef]

31. Kulkarni, A.; Jana, S.C. Surfactant-free syndiotactic polystyrene aerogel foams via Pickering emulsion. Polymer 2020, $212,123125$. [CrossRef]

32. Ji, C.; Yao, B.; Li, C.; Shi, G. An improved Hummers method for eco-friendly synthesis of graphene oxide. Carbon 2013, 64, 225-229.

33. Dai, J.; Zhang, R.; Ge, W.; Xie, A.; Chang, Z.; Tian, S.; Zhou, Z.; Yan, Y. 3D macroscopic superhydrophobic magnetic porous carbon aerogel converted from biorenewable popcorn for selective oil-water separation. Mater. Des. 2018, 139, 122-131. [CrossRef] 
34. Jian, H.; Zhao, H.; Li, X.; Dong, S.; Zhang, F.; Ji, H.; Rui, L. Superelastic and superhydrophobic bacterial cellulose/silica aerogels with hierarchical cellular structure for oil absorption and recovery. J. Hazard. Mater. 2018, 346, 199-207.

35. Zhao, L.; Lian, L.; Wang, Y.; Wu, J.; Meng, G.; Liu, Z.; Guo, X. Preparation and characterization of thermo- and pH dual-responsive 3D cellulose-based aerogel for oil/water separation. Appl. Phys. A 2018, 124, 9. [CrossRef] 